Daniele Lanza, Ph. D in Cultural Studies University of Turin (Turin, Italy) dnl.lanza@gmail.com

\title{
IMAGES OF SIBERIA IN EUROPEAN CULTURE
}

\begin{abstract}
The article analyses views on Siberia that had been spread in European culture of the 18th 21 st centuries; describes the key political, ideological, and economic factors that had effect on forming and strengthening of such views in cultural consciousness of a historical and the today's European. Little-known for the Russian historiography parts of memoire and ethnographic literature written by foreigners who had personally visited Siberian territories are given. The author's view on genesis of true and false historical, cultural, and geographical stereotypes about Siberia is outlined.
\end{abstract}

Keywords: Europeans' views on Siberia, cultural stereotypes about Siberia, foreign travelers' memoires about Siberia, European press about Siberia, Siberia as a Russian cultural brand, mass culture, mass consciousness, Siberia, Altai, Europa, European culture, an image in culture, a cultural stereotype.

\section{References}

1. Leonov, I. V. Etno-tradicionnyj suvenir v prostranstve massovoj kul'tury [Ethnotraditional Souvenir in Mass Culture] / I. V. Leonov, V. L. Solov'yova // Vestnik Sankt-Peterburgskogo gosudarstvennogo instituta kul'tury [Bulletin of Sain Petersburg State Institute of Culture]. 2019. No. 1. Pp. 93-98. [In Russ.].

2. Leonov, I. V. Kul'turnoe prostranstvo i osnovnye puti ego modelirova-niya [Cultural Space and The Main Ways to Modelling It] / I. V. Leonov, M. A. Haritonova // Chelovek. Kul'tura. Obrazovanie [Human. Culture. Education]. 2018. No. 3. Pp. 100-115. [In Russ.].

3. Bassin M. Inventing Siberia: Visions of the Russian East in the Early Nineteenth Century // The American historical review. 1991. Vol. 96, no. 3. Pp. 763-794.

УДК 316.347:008:745/749

DOI: 10.32340/2514-772X-2019-1-82-87
4. Gruzdeva A. S. An image of Siberia in Contemporary Foreign Photography (the 90s of the $20^{\text {th }}$ Century-the First Decade of the $21^{\text {th }}$ Century) // Journal of Siberian Federal University. Humanities \& Social Sciences. 2017. Vol. 10, no. 2. Pp. 255270.

5. Gryaznuhina, T. V. Impact of Social Stereotypes on the Perception of Siberia by Inhabitants of European Russia in the $19^{\text {th }}$ Century / T. V. Gryaznuhina, A. B. Gryaznuhin // Journal of Siberian Federal University. Humanities \& Social Sciences. 2013. Vol. 10, no. 6. Pp. 1461-1470.

6. Love R.S. «A Passage to China»: A French Jesuit's Perceptions of Siberia in the 1680s // French Colonial History. 2003. Vol. 3: Idea and Action in French Colonization. Pp. 85-100. \section{Санкт-Петербургский государственный институт культуры, Государственный литературно-мемориальный музей Анны Ахматовой в Фонтанном Доме (Санкт-Петербург, Россия) ivaleon@mail.ru}

И. В. Леонов, доктор культурологии,

\section{РЕПРЕЗЕНТАЦИИ ТРАДИЦИОННЫХ КУЛЬТУР В ИНДУСТРИИ СУВЕНИРОВ}

Аннотация. Представлен анализ современного состояния и основных направлений развития современной отечественной индустрии этно-традиционных и историко-культурных сувениров. Рассмотрен феномен зависимости ассортимента сувенирной продукции от степени устойчивости стереотипов в массовом культурном сознании в отношении исторической и современной России, отдельных историко-культурных зон страны. Охарактеризован эффект влияния художественно-эстетического облика сувенирной продукции на формирование представлений потребителей о культурных особенностях народов, населяющих современное российское государство. Затронут вопрос о допустимых пределах «искажений» отечественных историко-культурных реалий, возникающих из-за присутствия на рыке некачественных этно-традиционных сувениров.

Ключевые слова: сувенир, артефакт, индустрии культуры, историко-культурный процесс, визуальный образ, гуманитарные технологии, репрезентация традииионной культуры, историкокультурная репрезентативность сувенира. 
В современной индустрии сувениров отдельное место занимают артефакты, призванные представлять потребителям те или иные традиционные культуры, а также определенные «историко-культурные зоны». Продукция данного вида проявляет себя достаточно ярко во всех регионах мира, так или иначе соприкасающихся с туристической индустрией.

Как таковой сувенир выступает предметом, напоминающим об определенной ушедшей или далеко существующей реальности. Особую значимость в сувенире имеют не его материальные, внешние характеристики, а те воспоминания и ассоциации, которые он пробуждает в воображении человека. Сувенир это своеобразная «зацепка» для памяти, то, что позволит пробудиться привязанной к сувениру информации в сознании владельца. Разумеется, внешние особенности такого рода предметов могут иметь материальную, художественную и иную ценность, но повод вспомнить, обратившись к сувениру, в большинстве случаев преобладает.

Отправляясь куда-либо или переживая какие-то состояния в ограниченном ареале, человек приобщается к соответствующим топохронам, «отделяя» их части и присваивая себе. Во многом это становится проявлением целой серии архетипов, укорененных в сознании человека: фетишизма; коллективной трапезы и приобщения через пищу; отделения образа от носителя с целью манипулирования данным образом; приобщения к месту при помощи изменения своего внешнего вида и т. д. Жилище современного человека наполнено подобного рода артефактами, «сообщающими» ему о том, что он пережил. Примечательно, что такими предметами может выступать что угодно еловая шишка из пионерского лагеря, ракушка с моря, школьный дневник, детский рисунок, монета, оказавшаяся в какой-то момент времени в кармане и прочее. Главное, что у человека налаживается связь с другой реальностью через соответствующий предмет в его воображаемом мире.

Своеобразные «витрины» жизненного опыта отдельного человека, состоящие из сувениров и других «зацепок для памяти», являются немаловажным атрибутом современной культуры повседневности. Как правило, данные артефакты группируются в целые комплексы, получая воплощение в интерьере, одежде и даже в социальных сетях. С их по- мощью может быть сохранен и «разбужен» профессиональный, географический, историко-культурный, социальный, семейный, гастрономический, спортивный, охотничий и многие другие виды опыта. К примеру, в последние десятилетия достаточно популярной витриной географического опыта, пришедшей на смену чемоданам с соответствующими наклейками, стали холодильники, увешанные магнитами из разных мест.

Возвращаясь к основной идее статьи, к сувенирам, репрезентующим традиционные культуры и отдельные историко-культурные зоны, отметим, что их роль в формировании общих представлений современного человека о данных гранях реальности чрезвычайно высока. На первый взгляд, такой вывод может показаться несколько странным, поскольку сувениры, в основном будучи достаточно недорогими и тривиальными безделушками, не претендуют на роль артефактов, имеющих для формирования представлений об этнотрадиционных и исторических аспектах культуры системообразующий характер. Индустрия сувениров для многих живет сама по себе, безобидно бытуя в пространстве массовой культуры, развлекая и скрашивая досуг потребителя. Тем не менее, культурологический анализ рассматриваемого влияния показывает, что сувенир в данном плане нельзя недооценивать. На отраслевом уровне наук, занимающихся проблематикой культуры, которые в современном знании принято именовать культуроведением, такие аспекты видны не всегда. Однако генерализация многообразия различных граней проблематики представленных сувениров раскрывает широкий спектр эвристических, экспертных и практических возможностей, рождаемых в ходе изучения рассматриваемой индустрии. Отдельно следует указать на то, что индустрия сувениров, будучи очень популярной во всем мире, имеет большой потенциал в сфере «гуманитарных технологий», которые в начале XXI века обрели «тотальный характер и модус парадигмы культуры, настойчиво заявляя о себе всюду» $[4$, c. 10$]$.

В первую очередь, характеризуя современную сувенирную продукцию в изучаемой сфере, необходимо указать на ее глубокую интегрированность в пространство массовой культуры и тесную связь с рынком. Отмеченное обстоятельство максимально искажает этно-традиционные и историко-культурные су- 
вениры, порой до полного нивелирования их материальной и смысловой нагрузки. «Мутировавший» таким образом сувенир перестаёт представлять потребителю соответствующую культуру или топохрон, он начинает превращаться во что угодно (именную ложку, «снежный шар», открывалку для бутылок, «денежную лягушку», «кошельковую мышь» и пр.), вливаясь в безликое пространство «вещей, купленных где-то». Акцент на прибыль, удешевление производства, привлечение широкого круга потребителей, следование «массовому вкусу» и многие другие обстоятельства превращают рассматриваемую группу сувениров в малограмотную и однотипную «пластмассовую имитацию».

Одним из характерных признаков данных «мутаций» является гипертрофированность визуальных сторон сувенирной продукции, яркость которой порой делает аутентичные памятники, хранящиеся в музеях и до сих пор встречаемые в пользовании, неприглядными и блеклыми. Пестрящие красками, порой неестественных цветов и оттенков, сувенирные изделия для многих потребителей становятся эталоном красоты, качества и подлинности. Кроме того, визуальный образ, став основой репрезентации традиционных культур, все чаще отрывается от своих исконных носителей, размещаясь на любых предметах. При этом сами образы постоянно преобразуются и дополняются, «размывая» хрупкую грань между их традиционными и инновационными проявлениями. Ещё одним маркером трансформаций сувениров является замена их материалов более дешёвыми, в первую очередь, пластмассовыми. Здесь же уместно указать на недостаточный уровень этно-традиционной и историко-культурной грамотности массового потребителя, не способного отделить сувенирную продукцию, близкую аутентичной и полностью ей противоречащую. Одним из последствий данной тенденции является смешение традиций разных культур в сувенирах, суть которых сводится к межкультурному «псевдоморфозу», то есть к дисгармоничному «сращиванию» форм и смысловых нагрузок различных культур в рамках одного артефакта. Ещё одной особенностью искажений рассматриваемых сувениров является нацеленность данной индустрии на «ожидаемые образы» и стереотипы, укорененные в сознании потребителей. Перечисление отмеченных «мутагенных» фак- торов сувенирной продукции можно продолжать достаточно долго, однако названного вполне достаточно, чтобы обозначить ее невероятную хрупкость, пластичность и изменчивость. Тем не менее, в рамках представленной статьи уместно сосредоточиться не только на критике происходящих в индустрии сувениров процессов, но и на их анализе с позиций гуманитарных технологий, направленных на формирование представлений об этнотрадиционных и исторических аспектах разных культур.

В первую очередь важно указать на высокую степень доверия, которая проявляется на уровне массовой культуры в отношении изучаемых «репрезентантов». В основном потребитель искренне верит, что приобретает аутентичный продукт, напоминающий ему в дальнейшем об «иной реальности», причём данный продукт влияет и на других потребителей, соприкасающихся с ним. На массовом уровне такие артефакты, «гнездясь» в пространстве повседневности, пассивно влияют на общество в целом, формируя его представления о тех или иных культурах. Особенно ярко такие процессы проявляются в культуpax, ставших на инновационный путь развития и утрачивающих свои традиционные основания. Их прошлое начинает жить не только в аутентичных вещах, но и в их «подобияХ». С течением времени такие вещи начинают сами формировать представления о прошлом на уровне соответствующих форм, образов и смыслов. При этом в случае искажения данных вещей, искажается и прошлое. Указанная зависимость показывает, что индустрия сувениров нуждается в комплексной экспертизе на предмет органического соответствия ее продукции тем культурам и территориям, которые она репрезентирует.

Достаточно эффективный путь коррекции отмеченной сферы представляет выстраивание «защитного пояса» вокруг визуальных образов «культурных организмов», сферы, которая подвержена наиболее высоким скоростям «загрязнения». В отмеченном случае достаточно упомянуть работы В. Беньямина и Дж. Бёрджера $[1 ; 2]$, убедительно показавших связь визуальных образов определенных культур с мировоззрением их представителей, включая анализ процессов трансформации образов, влекущих соответствующие мировоззренческие изменения. 
Особую трудность в анализе рассматриваемой сферы представляет определение степени ее допустимой инновационности. Дело в том, что полностью законсервировать «мутации» изучаемых сувениров невозможно и нецелесообразно. Степень обновления культуры в ходе культурогенеза не может быть сведена к нулю. Инновации, так или иначе, проявляют себя в любой культуре, даже в самой, на первый взгляд, традиционной. Показательно в данном случае, что многие сферы русской культуры, воспринимаемые сейчас как традиционные, являют собой инновации нескольких последних столетий. Достаточно упомянуть борщ, самовар, балалайку, Петрушку, матрёшку, существенные трансформации лаковых промыслов в начале $\mathrm{XX}$ века [3, с. 72] и т. д. В этом смысле многие современные новшества, которые проникают в изучаемую сферу, имеют шансы на постепенное укоренение в «ткани» самой культуры. Однако когда степень данных проникновений превышает допустимые для ее сохранения и трансляции показатели, наступает угроза постепенного «размывания» традиционных основ культуры, вплоть до возможной утраты ее самости.

К некоторым направлениям «расширения» этно-традиционной сферы, обнаруживающим своё проявление и на уровне соответствующих сувениров, относится включение в ее пространство исторических событий, биографий известных личностей, достижений в сфере академического искусства, особенностей региональной промышленности, природноклиматической специфики «места развития» и т. д. В результате чёткая граница между этно-традиционным и современным приходит в движение. Так, в российском суперэтносе важнейшей духовной скрепой стала победа в Великой Отечественной войне, в этносферу вошёл русский балет, полет Гагарина и т. д.; в самоидентификации современных алтайцев особое значение обрёл художник Чорос Гуркин; у якутов делается акцент на алмазодобывающую промышленность и т. д. Характерно, что с течением времени названные компоненты этносферы постепенно погружаются в традиционную часть. Примером данной тенденции является размещение образов, связанных с Новой и Новейшей историей России, на матрёшках. В результате матрёшка с фотографическим изображением Эрмитажа, Петергофа или космодрома «Восточный» становится комбинированным этно-традиционным сувениром.

Сейчас достаточно часто можно встретить сувениры, которые, при наличии определённых эстетических качеств, сделаны по «этническим мотивам». Такую продукцию нельзя назвать абсолютно «пустой» в этнокультурном плане. Но степень подобных «художественных изысканий» и «преломлений», не нарушающую связь сувенира с его реальностью на уровне баланса эстетического, исторического, этнографического и других аспектов, уловить достаточно трудно. Многочисленные фляжки с изображениями стилизованных под советскую мультипликацию домовых, леших и других персонажей; живописные и скульптурные сюжеты на этно-традиционные темы, выполненные в рамках европейской художественной традиции и подаваемые как традиционноэтнические; артефакты, содержащие смешения языческих и религиозных сюжетов и символов; «игры» с этническими и историческими мотивами, ассоциациями и аллюзиями; напластования разновременного и другие примеры ставят задачу их ранжирования на более-менее грамотные и далёкие от этого уровня. В данном случае необходимо ориентироваться на то, что изготавливается, из какого материала, какой образ и на чем располагается, каковы искажения первоначального вида, кем и по каким технологиям изготовлен артефакт и пр. Вопрос разработки экспертных стратегий в данном направлении хоть и медленно, но получает своё развитие в современных культурных индустриях. Наиболее убедительным примером такой деятельности является Республика Саха (Якутия), где на уровне власти делается многое для сохранения аутентичных промыслов, включая их присутствие на индустриальном уровне с минимальной долей допустимых трансформаций.

Достаточно продуктивным технологическим вектором, направленным на формирование мировоззрения потребителей этнотрадиционной сувенирной продукции, является картирование территорий и демонстрация их флоры и фауны. Характерно, что сувениры, представляющие данную группу, не всегда типичны для определённых культур, представляя продукцию совершенно нового типа. К примеру, во многих номадических и земледельческих культурах не принято производить и продавать кухонные доски, кружки и магни- 
ты с изображением географических карт или определённых животных (скажем, снежного барса, медведя или рыси). Однако, эффект от такого моделирования носит максимально позитивный характер. Знание природногеографических особенностей регионов рождает в сознании человека модель «места развития» или «экологических ниш» определённых культур, близкую к ощущению окружающего пространства у людей, живущих в данных «нишах». Более того, если указанные модели пространства дополняются историкокультурными аспектами, в сознании потребителей может сформироваться целостный природный и историко-культурный образ («гештальт»), отражающий условия жизни и биографии определённых «культурных организмов».

Эффективным вектором популяризации традиционных аспектов культуры является акцент на некоторые направления индустрии сувениров, которые находятся на пике масскультовской популярности. Одним из таких аспектов является кухня. Напитки, традиционные продукты и блюда долгого хранения становятся настоящей визитной карточкой разных регионов. Даже быстропортящиеся продукты, попадая в сферу сувениров, получают соответствующую своему статусу обёртку с размещёнными на ней образами или украшениями, заставляя потребителя хранить ее и пробуждать в памяти определённые ассоциации. Здесь же следует упомянуть сувениры, содержащие запахи, сила влияния которых на человека в настоящее время по достоинству не оценена. Однако в данных сферах помимо положительных примеров (Алтай - мёд, сыр, кедр, можжевельник, сосна) также наблюдается высокий уровень неаутентичности и стереотипизированности. Так, водка и пиво как маркер региональной культуры используются не всегда уместно. В случае с Алтаем более целесообразно делать акцент на бальзамы и настои из трав.

Отдельного внимания заслуживают разновидности этно-традиционных сувениров, которые могут не только пассивно «напоминать» о чем-либо, но и использоваться по прямому утилитарному назначению. Данные сувениры могут утрачивать свою «сувенирную функцию», превращаясь в бытовые, хозяйственные и иные вещи. Ввиду того, что современная культура находится в «режиме постоянного обновления» и многие ее традиционные аспек- ты ввергаются в поток инноваций просто потому, что таковы ее ценностные ориентиры, многие традиционные артефакты, образы и смыслы без особой необходимости морально устаревают и замещаются чем-либо иным. Залегая в археологии прошлых форм такие феномены «умирают», становясь экспонатами, несправедливо выведенными за пределы «диалога» с настоящим. Вернуть указанные феномены в актуальное поле культуры вполне по силам, если они получат импульс популяризации со стороны заинтересованных сил, в том числе сферы культурных индустрий. Повседневная культура изобилует такими нишами, вполне способными включить ее традиционные основы, достаточно далекие от простых «стилизаций по мотивам»: декорированные деревянные скалки, берестяные туеса, кумысники, керамика, орнаментальные формы полотенец и скатертей, игрушки, валенки, ювелирные украшения, подносы и многие другие феномены, проникнув в быт, могут принять участие в сохранении традиционного культурного «генома».

Помимо названных существуют и другие направления актуализации традиционных аспектов культуры через сувениры. И в каждом случае найдутся как положительные, так и отрицательные стороны. Простых рецептов и стратегий к действию в данной области нет, она противоречива, чувствительна к изменениям и постоянно трансформируется. Тем не менее, «держать руку на пульсе», давать комплексную оценку происходящему, разрабатывать соответствующие рекомендации, искать пути коррекции и развития изучаемой сферы в интересах государственной культурной политики и национальных приоритетов, современная гуманитаристика, включая культурологию, вполне способна.

Список литературы

1. Беньямин, В. Произведение искусства в эпоху его технической воспроизводимости. Избранные эссе. Москва, 1996. 240 с.

2. Бергер, Дж. Искусство видеть. СанктПетербург, 2012. 184 с.

3. Махлина, С. T. Палех вчера и сегодня // Петербургские искусствоведческие тетради. Санкт-Петербург, 2017. Вып. 43. С. 70-85.

4. Tхагапсоев, X. Г. Идентичность как навигатор сознания / Х. Г. Тхагапсоев, Л. М. Мосолова, И. В. Леонов, В. Л. Соловьёва. Санкт-Петербург, 2016. $170 \mathrm{c}$. 
Ivan V. Leonov, Dr. of Cultural Studies, Sankt Petersburg State Institute of Culture, The Anna Akhmatova Literary and Memorial Museum in Fountain House

(Saint Petersburg, Russia) ivaleon@mail.ru

\title{
REPRESENTATION OF TRADITIONAL CULTURES IN SOUVENIR INDUSTRY
}

\begin{abstract}
The article analyses the current state and the key directions of development of the modern Russian industry of ethnic, historical, and cultural souvenirs. The phenomenon of dependence between a range of souvenir products and strength of stereotypes in cultural consciousness towards the historical and today's Russia, its historical and cultural zones. The author discloses an effect of influence of artistic and aesthetic image of souvenir products on buyers' views on cultural peculiarities of peoples of the today's Russia, touches an issue about permissible limits of falsification of Russian historical and cultural reality that appears because of low-quality souvenir products in market.

Keywords: a souvenir, an artefact, fields of culture, historical and cultural process, a visual image, humanitarian technologies, representation of a traditional culture, historical and cultural representativeness of a souvenir.
\end{abstract}

\section{References}

1. Benjamin, V. Proizvedenie iskusstva v epohu ego tekhnicheskoj vosproizvodimosti. Izbrannye esse [The Work of Art in the Age of Mechanical Reproduction] Moscow, 1996. 240 c. [In Russ.].

2. Berger, J. Iskusstvo videt' [Ways of Seeing].Saint Petersburg, 2012. 184 c. [In Russ.]

3. Mahlina S. T. Palekh vchera i segodnya [Palekh Miniature Yesterday and Tomorrow] //
Peterburgskie iskusstvovedcheskie tetrad [Petersburg Notebooks in Art of Criticism]. Saint Petersburg, 2017. Is. 43. Pp. 70-85. [In Russ.].

4. Thagapsoev, H. G. Identichnost' kak navigator soznaniya [Identity as a Way Finder for Consciousness] / H. G. Thagapsoev, L. M. Mosolova, I. V. Leonov, V. L. Solov'yova. Saint Petersburg, 2016. 170 p. [In Russ.].

УДК 82-131(470.55)=512.1

DOI: $10.32340 / 2514-772 X-2019-1-87-96$

Л. Х. Мухаметзянова, доктор философских наук, доцент Институт языка, литературы и искусства им. Г. Ибрагимова Академии наук Республики Татарстан (Казань, Россия) lilmuhat@mail.ru

\section{МЕЖДУ ВОЛГОЙ И УРАЛОМ: ЭПИЧЕСКИЕ ЦЕННОСТИ ТАТАР И БАШКИР, ПРОЖИВАЮЩИХ В ЧЕЛЯБИНСКОЙ ОБЛАСТИ РОССИЙСКОЙ ФЕДЕРАЦИИ}

Аннотация. Раскрыто содержание наиболее популярных сюжетных конструкций дастанов эпических произведений татарского и башкирского народного творчества; проанализированы некоторые сюжетные особенности известных дастанов. Отмечена связь между миграцией части татарского и башкирского этносов в сибирский регион и жанровыми трансформациями дастанов. Представлены фрагменты нотных записей достанов «Йосыф китабыl», «Сайфульмулюк», «Буз егет» и др. Охарактеризованы направления работы Институт языка, литературы и искусства им. Г. Ибрагимова Академии наук Республики Татарстан (г. Казань, Россия) в области сбора, научного анализа и популяризации образцов дастанов.

Ключевые слова: фольклор тюркских народов России, татарский фольклор, башкирский фольклор, татарский эпос, башкирский эпос, дастан, сюжет достана, фольклорная экспедиция, Институт языка, литературы и искусства им. Г. Ибрагимова Академии наук Республики Татарстан.

Дастан - эпический жанр в татарском и башкирском народном творчестве, эквивалентный понятию эпос в фольклористике. В начальной стадии своего развития дастаны передавались устно сэсэнами или чичянами- импровизаторами. Эти произведения пользовались большой популярностью; кочуя из столетия в столетие, из поколения в поколение, они практически сохранились в своем первозданном виде. Эпос татар и башкир уходит 